\section{Celestial driver of Phanerozoic climate?}

\author{
Nir J. Shaviv, Racah Institute of Physics, Hebrew University of Jerusalem, Jerusalem, \\ 91904, Israel
}

Ján Veizer, Institut für Geologie, Mineralogie und Geophysik, Ruhr Universität, 44780 Bochum, Germany, and Ottawa-Carleton Geoscience Centre, University of Ottawa, Ottawa, Ontario K1N 6N5, Canada

\begin{abstract}
Atmospheric levels of $\mathrm{CO}_{2}$ are commonly assumed to be a main driver of global climate. Independent empirical evidence suggests that the galactic cosmic ray flux $(\mathrm{CRF})$ is linked to climate variability. Both drivers are presently discussed in the context of daily to millennial variations, although they should also operate over geological time scales. Here we analyze the reconstructed seawater paleotemperature record for the Phanerozoic (past 545 m.y.), and compare it with the variable CRF reaching Earth and with the reconstructed partial pressure of atmospheric $\mathrm{CO}_{2}\left(p \mathrm{CO}_{2}\right)$. We find that at least $66 \%$ of the variance in the paleotemperature trend could be attributed to CRF variations likely due to solar system passages through the spiral arms of the galaxy. Assuming that the entire residual variance in temperature is due solely to the $\mathrm{CO}_{2}$ greenhouse effect, we propose a tentative upper limit to the long-term "equilibrium" warming effect of $\mathrm{CO}_{2}$, one which is potentially lower than that based on general circulation models.
\end{abstract}

\section{CLIMATE ON GEOLOGICAL TIME SCALES}

The record of climate variations during the Phanerozoic (past 545 m.y.), based on temporal and spatial patterns of climatesensitive sedimentary indicators, shows intervals of tens of millions of years duration characterized by predominantly colder or predominantly warmer episodes, called icehouses and greenhouses (Frakes et al., 1992), respectively (Fig. 1). Superimposed on these are higher-order climate oscillations, such as the waning and waxing of ice sheets during the past $1 \mathrm{~m} . \mathrm{y}$. The recurring icehouse/greenhouse intervals were postulated to be a consequence of a plethora of causative factors, from celestial to plan- etary, including geographic distribution of continents, oceanic circulation patterns, atmospheric composition, or any combination of these. Lately, the consensus opinion favors atmospheric $\mathrm{CO}_{2}$ as a principal climate driver for most time scales, from billions of years $\left(\mathrm{CO}_{2}\right.$ supergreen- house, snowball Earth [Kasting and Ackerman, 1986; Hoffman et al., 1998]), to decadal and annual (Intergovernmental Panel on Climate Change [IPCC], 2001). Past climate variations should therefore correlate positively with coeval atmospheric $p \mathrm{CO}_{2}$ levels.

For the Phanerozoic, estimates of atmospheric $p \mathrm{CO}_{2}$ levels (Fig. 1) are based on model consideration and proxy data. Presently, three such estimates exist: the GEOCARB III model (Berner and

Kothavala, 2001) and its precursors, and the reconstructions of Berner and Streif (2001) and Rothman (2002). These reconstructions rely, to a greater or lesser degree, on the same isotope databases of Veizer et al. (1999). However, they produce internally inconsistent outcomes and the curves do not show any clear correlation with the paleoclimate record.

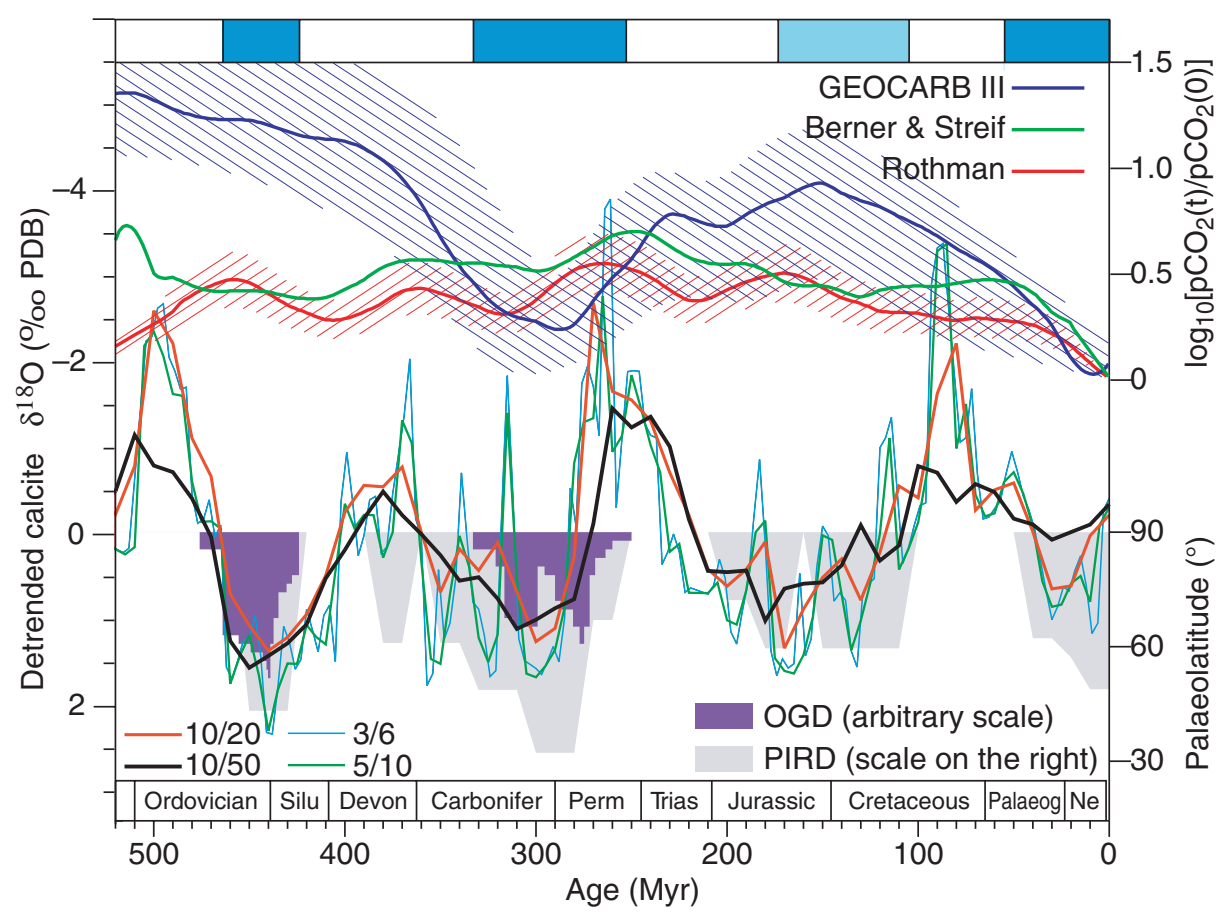

Figure 1. Phanerozoic climatic indicators and reconstructed $p \mathrm{CO}_{2}$ levels. The bottom set of curves are the detrended running means of $\delta^{18} \mathrm{O}$ values of calcitic shells over the Phanerozoic (Veizer et al., 2000). 3/6, 5/10, 10/20 and 10/50 indicate running means at various temporal resolutions (e.g., 3/6 means step 3 m.y., window 6 m.y. averaging). The paleolatitudinal distribution of ice rafted debris (PIRD) is on the right-hand vertical axis. The available, Paleozoic, frequency histograms of other glacial deposits (OGD)— such as tillites and glacial marine strataare dimensionless. The blue bars at the top represent cool climate modes (icehouses) and the white bars are the warm modes (greenhouses), as established from sedimentological criteria (Frakes and Francis, 1998; Frakes et al., 1992). The lighter blue shading for the JurassicCretaceous icehouse reflects the fact that true polar ice caps have not been documented for this time interval. The upper set of curves describes the reconstructed histories of the past $p \mathrm{CO}_{2}$ variations (GEOCARB III) by Berner and Kothavala (2001), Berner and Streif (2001) and Rothman (2002). The $p \mathrm{CO}_{2}(0)$ is the present-day atmospheric $\mathrm{CO}_{2}$ concentration. All data are smoothed using a running average of 50 m.y. with 10 m.y. bins. The hatched regions depict the uncertainties quoted in the Rothman and the GEOCARB reconstructions. 
The poor correlation of the modeled $p \mathrm{CO}_{2}$ with the observed Phanerozoic climate trends (Frakes et al., 1992; Veizer et al., 2000; Boucot and Gray, 2001) suggest either that the $\mathrm{pCO}_{2}$ models may be in need of improvement, or, if one of them is validated, that the $\mathrm{CO}_{2}$ is not likely to be the principal climate driver. In that case, what could be an alternative driving force of climate on geological time scales?

Decompositions of the $\delta^{18} \mathrm{O}$ and paleoclimate trends ${ }^{1}$ (Veizer et al., 2000) display a dominant cyclic component of $\sim 135 \pm 9$ m.y. For $\delta^{18} \mathrm{O}$, this is regardless of the temporal resolution (on m.y. time scales) adopted for deconvolution of the signal. There are no terrestrial phenomena known that recur with this frequency, particularly taking into account the regular near-sinusoidal fashion (Fig. 1; Wallmann, 2001) of the $\delta^{18} \mathrm{O}$ data. This regular pattern implies that we may be looking at a reflection of celestial phenomena in the climate history of Earth.

\section{CELESTIAL CLIMATE DRIVER}

Growing evidence, such as the correlations between paleoclimate records and solar and cosmic ray activity indicators (e.g., ${ }^{10} \mathrm{Be},{ }^{14} \mathrm{C}$ ), suggests that extraterrestrial phenomena are responsible for at least some climatic variability on time scales ranging from days to millennia (Friis-Christensen and Lassen, 1991; Tinsley and Deen, 1991; Soon et al., 1996; Svensmark, 1998; Beer et al., 2000; Egorova et al., 2000; Soon et al., 2000; Björck et al., 2001; Bond et al., 2001; Hodell et al., 2001; Kromer et al., 2001; Labitzke and Weber, 2001; Neff et al., 2001; Todd and Kniveton, 2001; Pang and Yau, 2002; Solanki, 2002). These correlations mostly surpass those, if any, for the coeval climate and $\mathrm{CO}_{2}$. Empirical observations indicate that the climate link could be via solar wind modulation of the galactic cosmic ray flux (CRF) (Tinsley and Deen, 1991; Svensmark, 1998; Marsh and Svensmark, 2000; Todd and Kniveton, 2001; Shaviv, 2002a, 2002b) because an increase in solar activity re- sults not only in enhanced thermal energy flux, but also in more intense solar wind that attenuates the CRF reaching Earth. The CRF, in turn, correlates convincingly with the low-altitude cloud cover on time scales from days (Forbush phenomenon) to decades (sun spot cycle). The postulated causation sequence is therefore: brighter sun $\Rightarrow$ enhanced thermal flux + solar wind $\Rightarrow$ muted $\mathrm{CRF} \Rightarrow$ less lowlevel clouds $\Rightarrow$ less albedo $\Rightarrow$ warmer climate. Diminished solar activity results in an opposite effect. The apparent departure from this pattern in the $1990 \mathrm{~s}$ (Solanki, 2002) may prove to be a satellite calibration problem (Marsh and Svensmark, 2003). The CRF-cloud-coverclimate link is also physically feasible because the CRF governs the atmospheric ionization rate (Ney, 1959; Svensmark, 1998), and because recent theoretical and experimental studies (Dickenson, 1975; Harrison and Aplin, 2001; Eichkorn et al., 2002; Yu, 2002; Tinsley and Yu, 2003) relate the CRF to the formation of charged aerosols, which could serve as cloud condensation nuclei (CCN), as demonstrated independently by ground-based and airborne experiments (Harrison and Aplin, 2001; Eichkorn et al., 2002).

Despite all these empirical observations and correlations, the solar-CRF-climate link is still missing a robust physical formulation. It is for this reason that such a link is often understated (IPCC, 2001), but this may change when the advocated experimental tests (Kirkby, 2001) are carried out. The only solar-climate mechanism that presently has a robust understanding, is change in the integrated solar luminosity, but the centennial increase in solar constant ( 2-4 $\mathrm{W} \mathrm{m}^{-2}$ : Pang and Yau, 2002; Solanki, 2002) appears to have been insufficient to account for the observed $\sim 0.6^{\circ} \mathrm{C}$ temperature increase (IPCC, 2001). An amplifier, such as the cloud/ CRF link, is therefore required to account for the discrepancy. Note, however, that a similar, albeit not as large, amplifier is implicit also in the $\mathrm{CO}_{2}$ alternative, because the centennial temperature rise in these models is due mostly to the potential, and to some extent theoretical, positive water vapor feedback (Pierrehumbert, 2002) coupled with "parameterized" clouds, not to the $\mathrm{CO}_{2}$ itself.

In view of the above empirical observations, could it be that the celestial forcing is the primary climate driver on most time scales, including the geological ones? The large stadial-interstadial temperature variations of the latest 420,000 $\mathrm{yr}$, which in the ice cores correlate with $\sim 80$ ppm variations in atmospheric $\mathrm{CO}_{2}$ (Petit et al., 1999), appear to argue against such an alternative. One should note, however, that it is not clear whether the $\mathrm{CO}_{2}$ is the driver or is being driven by climate change, particularly since the $\mathrm{CO}_{2}$ appears to lag by centuries behind the temperature changes (Petit et al., 1999; Fischer et al., 1999; Mudelsee, 2001; Monnin et al., 2001; Caillon et al., 2003; Clarke, 2003), thus potentially acting as an amplifier but not as a driver. Can the geological record shed more light on this conundrum?

Unlike the past century, where solar activity, atmospheric $\mathrm{CO}_{2}$, and global temperatures were predominantly increasing, and unlike the ice cores with their unresolved cause and effect relationship of $\mathrm{CO}_{2}$ and climate, the situation over the Phanerozoic is different, with all three variables exhibiting a non-monotonic behavior. This may enable decomposition of the global temperature changes into contributions from $\mathrm{CO}_{2}, \mathrm{CRF}$, and a residual. It may also help to settle the causative sequence because celestial phenomena cannot be driven by terrestrial forcing. Moreover, the inherent time scales required for the global climate system to reach equilibrium can be as large as several millennia, owing to the slow heat exchange between the oceans and the atmosphere, and to the slow ice sheet adjustment time. Thus, by estimating the effects of $\mathrm{CO}_{2}$ over geological time scales, we may obtain the long-term "equilibrium" response of the global climate system.

Recently, Fields and Ellis (1999) and

\footnotetext{
${ }^{1}$ The oxygen isotope record is based on 4500 measurements of shells (brachiopods, belemnites, foraminifera) composed of low-Mg calcite, the carbonate phase most resistant to post-depositional overprint of the signal. The data show a secular ${ }^{18} \mathrm{O}$ depletion trend with age, with superimposed higher order oscillations and it is these that are in phase with reconstructions of the Phanerozoic climate. The major features of these oscillations represent a robust signal in and of themselves, which would be reproduced even if only a fraction of the samples, those near the upper envelope of the secular trend, were taken into consideration. It is this detrended oscillating pattern, with correction scaled for ice volume effect, that yields the Phanerozoic $\Delta T\left[{ }^{\circ} \mathrm{C}\right]$ variations for contemporaneous low-latitude shallow sea water in Figure 2.
} 


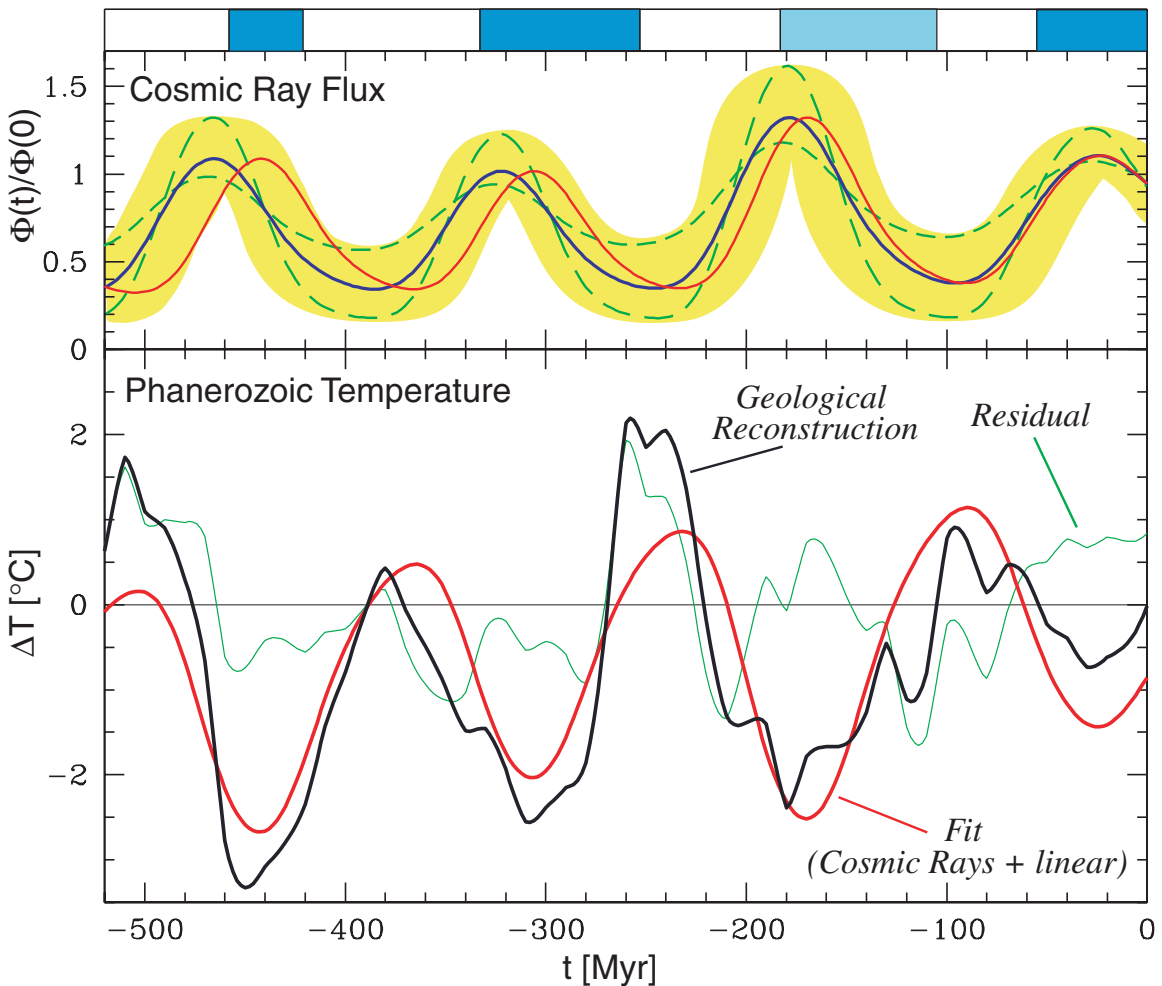

Figure 2. The cosmic ray flux $(\Phi)$ and tropical temperature anomaly $(\Delta T)$ variations over the Phanerozoic. The upper curves describe the reconstructed CRF using iron meteorite exposure age data (Shaviv, 2002b). The blue line depicts the nominal CRF, while the yellow shading delineates the allowed error range. The two dashed curves are additional CRF reconstructions that fit within the acceptable range (together with the blue line, these three curves denote the three CRF reconstructions used in the model simulations). The red curve describes the nominal CRF reconstruction after its period was fine tuned to best fit the low-latitude temperature anomaly (i.e., it is the "blue" reconstruction, after the exact CRF periodicity was fine tuned, within the CRF reconstruction error). The bottom black curve depicts the 10/50 m.y. (see Fig. $1)$ smoothed temperature anomaly $(\Delta T)$ from Veizer et al. (2000). The red line is the predicted $\Delta T_{\text {model }}$ for the red curve above, taking into account also the secular long-term linear contribution (term $B \times t$ in equation 1). The green line is the residual. The largest residual is at 250 m.y. B.P., where only a few measurements of $\delta^{18} \mathrm{O}$ exist due to the dearth of fossils subsequent to the largest extinction event in Earth history. The top blue bars are as in Figure 1.
Shaviv (2002a, 2002b) proposed that the CRF reaching the planet has not only an extrinsic variability due to its attenuation by solar wind, but also an intrinsic one arising from a variable interstellar environment. For example, a nearby supernova could bathe the solar system with a higher CRF for many millennia, leave a detectable ${ }^{60} \mathrm{Fe}$ imprint in ocean-floor deposits, and perhaps even give rise to a "cosmic ray winter" (Fields and Ellis, 1999) due to increased cloudiness and planetary albedo. Shaviv (2002a, 2002b) proposed that a particularly large CRF variability should arise from passages of the solar system through the Milky Way's spiral arms that harbor most of the star formation activity. Such passages recur at $\sim 143 \pm 10$ m.y. intervals, similar to the $135 \pm 9$ m.y. recurrence of the paleoclimate data (Veizer et al., 2000). Unlike the extrinsic solar-induced CRF modulations, which change the ionization rate at the bottom of the troposphere by typically $<10 \%$, the galactic flux variations are much larger and are expected to be about an order of magnitude more effective. It is these intrinsic CRF variations that may be responsible for the long-term climate changes over the past $1 \mathrm{Ga}$. Specifically, the "icehouses" and the oxygen isotope cold intervals (Fig. 1) appear to coincide with times of high CRF (Fig. 2), as deconvolved from galactic diffusion models and exposure ages in iron meteorites (Shaviv, 2002a, 2002b). The shorter-term annual to multi-millennial climatic effects, superimposed on this long-term baseline, would then reflect the extrinsic modulations of the CRF due to variable solar activity. Changes in orbital parameters and in solar and terrestrial magnetic fields may also potentially modulate this superimposed CRF-solar impact.

\section{CORRELATION OF THE CRF AND PALEOTEMPERATURE DATA}

In order to estimate the intrinsic CRF reaching Earth, we used a diffusion model that takes into account the geometry and dynamics of the spiral arms, and considers that cosmic rays are generated preferentially in these arms. We chose three sets of diffusion model parameters (Fig. 2) ${ }^{2}$, which span the entire range of CRF histories that are consistent with observational constraints, the latter limiting the period of CRF oscillations to $P_{0}=$ $143 \pm 10$ m.y. (Shaviv, 2002a, 2002b). Because the statistical record of exposure ages for iron meteorites has Poisson noise, the CRF histories we used are not directly extracted from it but they are the smoothed output of the galactic diffusion models constrained to fit the meteoritic record (see Shaviv 2002b for further caveats).

We model the temperature anomaly using the generalized form of:

$\Delta T_{\text {model }}=A+B \times t+C \times f\left(p \mathrm{CO}_{2}(t)\right)+D \times g\left(\Phi\left(t, P_{0}\right)\right)$

where $A, B, C, D, P_{0}$ are normalization parameters used to fit the observed $\Delta T_{\mathrm{i}}$.

The constant $A$ normalizes for the average $\Delta T$ while the term $B \times t$ describes a linear temporal trend in $\Delta T$. A term of this form is expected due to the increasing solar luminosity during the Phanerozoic, but may also arise from a possible secular variation in the CRF reaching the solar system; for example, from a changing star formation rate. A contribution to this term may also arise from systematic errors in the detrending procedure of the $\delta^{18} \mathrm{O}$ data. The third term considers the possibility that $\mathrm{CO}_{2}$ variations affect $\Delta T$, but at this stage we assume that the term is zero and defer its discussion to subsequent text. The fourth term arises

${ }^{2}$ The observational constraints (for $P_{0}=143 \pm 10$ m.y.) include the cosmic ray ${ }^{10} \mathrm{Be}$ age, and limits on CRF variations derived from iron meteorites. The three models that we utilize (Fig. 2) have a constant cosmic ray diffusion coefficient of $\mathrm{D}_{1,2,3}=0.1,0.3,1 \times 10^{28} \mathrm{~cm}^{2} / \mathrm{sec}$, and a galactic scale height of $\mathrm{l}_{1,2,3}=0.5,0.8$, and $1.5 \mathrm{kpc}$, respectively. 
TABLE 1: RESULTS FOR THE MINIMIZATION OF THE VARIANCE BETWEEN MODEL AND RECONSTRUCTED $\triangle T$.

\begin{tabular}{|c|c|c|c|c|c|c|c|c|c|}
\hline \multirow{2}{*}{$\begin{array}{c}\text { Model } \\
\text { no. }\end{array}$} & \multirow{2}{*}{$\begin{array}{c}\text { CRF } \\
\text { model }^{*}\end{array}$} & \multirow{2}{*}{$\begin{array}{c}\mathrm{CO}_{2} \\
\text { model }^{\dagger}\end{array}$} & \multicolumn{5}{|c|}{ Parameters minimizing $\sigma^{2 \S}$} & \multirow{2}{*}{$\begin{array}{l}\sigma_{\min }{ }^{2} \# \\
{\left[\left({ }^{\circ} \mathrm{C}\right)^{2}\right]}\end{array}$} & \multirow{2}{*}{$\begin{array}{c}\sigma_{18 \min }{ }^{*}{ }^{*} \\
{\left[\left({ }^{\circ} \mathrm{C}\right)^{2}\right]}\end{array}$} \\
\hline & & & $A\left[{ }^{\circ} \mathrm{C}\right]$ & $B\left[{ }^{\circ} \mathrm{C}\right]$ & $\mathrm{C}\left[{ }^{\circ} \mathrm{C}\right]$ & $D\left[{ }^{\circ} \mathrm{C}\right]$ & $P_{0}[\mathrm{Myr}]$ & & \\
\hline 1 & - & - & -0.68 & - & - & - & - & 96.3 & 18.5 \\
\hline 2 & - & - & -0.42 & 0.49 & - & - & - & 95.1 & 16.6 \\
\hline 3 & - & G & -0.38 & 0.37 & -0.03 & - & - & 95.0 & 14.7 \\
\hline 4 & - & $\mathrm{R}$ & 0.31 & 0.36 & -0.71 & - & - & 90.3 & 14.7 \\
\hline 5 & - & B & -0.75 & 0.02 & 0.11 & - & - & 100.4 & 15.3 \\
\hline 6 & (2) & - & -1.03 & 1.54 & - & -6.37 & 136.3 & 33.5 & 12.7 \\
\hline 7 & (2) & G & -0.76 & 0.69 & -0.26 & -6.50 & 136.2 & 32.1 & 10.8 \\
\hline 8 & (2) & B & -0.30 & 1.15 & -0.61 & -6.76 & 136.8 & 36.7 & 11.6 \\
\hline 9 & (1) & $\mathrm{R}$ & -0.56 & 1.17 & -0.38 & -3.74 & 135.5 & 33.0 & 10.8 \\
\hline 10 & (2) & $\mathrm{R}$ & -0.62 & 1.45 & -0.39 & -6.25 & 136.5 & 32.1 & 10.8 \\
\hline 11 & (3) & $\mathrm{R}$ & -0.41 & 2.06 & -0.42 & -11.70 & 134.8 & 32.1 & 10.8 \\
\hline \multicolumn{10}{|c|}{ 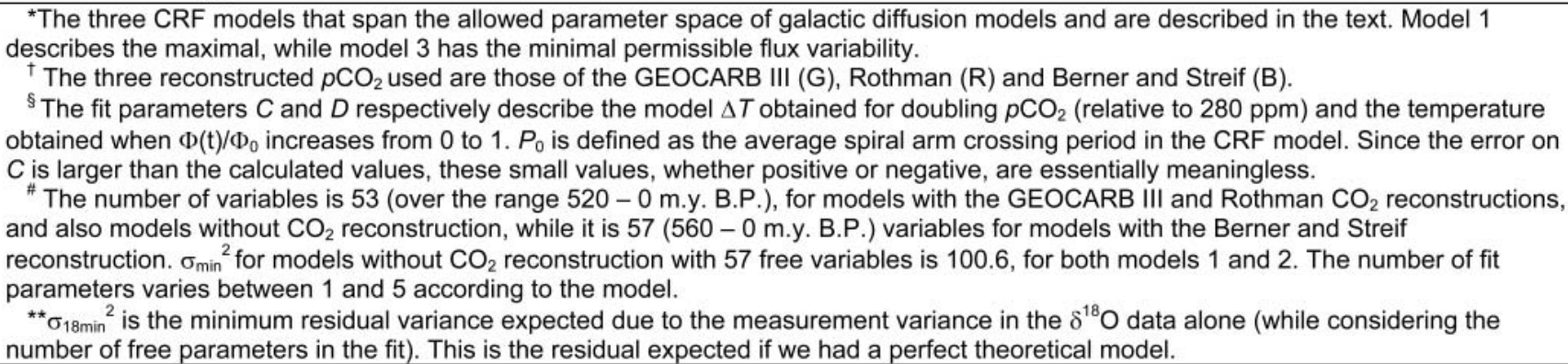 } \\
\hline
\end{tabular}

from the variable CRF $\Phi$, where $g(\Phi)$ describes the functional dependence between $\Delta T$ and $\Phi$, and $D$ is the actual normalization. ${ }^{3}$

All data (temperature, CRF, and the $\mathrm{CO}_{2}$ discussed later) are binned into 10 m.y. intervals and averaged using a 50 m.y. window running average. This is because the temporal resolution of the isotope databases and the derivative $p \mathrm{CO}_{2}$ models are in the $10^{6} \mathrm{yr}$ range, while that of the CRF is in the $10^{7} \mathrm{yr}$ range. Although Shaviv (2002a, 2002b) discussed the secular variations in CRF for the entire planetary history, the complementary $\delta^{18} \mathrm{O}$ record is available only for the Phanerozoic. We therefore truncate our comparison at 520 m.y. B.P. (560 m.y. for the Berner and Streif reconstruction). This gives us $N_{\text {meas }}=53$ (57) correlated $\Delta T_{\mathrm{i}}$ and their corresponding predicted $\Delta T_{\text {model }}\left(t_{\mathrm{i}}\right)$. Utilizing the three limiting models of CRF variations (Fig. 2), we tested our models by minimizing the residual variance between the model $\Delta T_{\text {model }}\left(t_{\mathrm{i}}\right)$ and the observed $\Delta T_{\mathrm{i}}$. We find that models that include solely the terms $A$ and $B$ result in a large $\sigma_{\min }{ }^{2}$ of $95\left({ }^{\circ} \mathrm{C}\right)^{2}$. However, once the term $D$, the CRF normalization, is included, the $\sigma_{\min }{ }^{2}$ reduces to $32-36\left({ }^{\circ} \mathrm{C}\right)^{2}$, in accord with the remarkable inverse correlation of CRF with the paleotemperature (Fig. 2). The CRF alone can explain $\sim 66 \%$ of the total variance in the temperature data. Can we further constrain the uncertainties in these models?

The only error on which we have a good handle is the statistical variance arising from the experimental $\delta^{18} \mathrm{O}$ data of Veizer et al. (1999). From the internal variance of the $\delta^{18} \mathrm{O}$ data within the bins, we can calculate $\sigma_{\min }{ }^{2}$ expected from this source of error. ${ }^{4}$ This would be the minimum residual statistically attainable if we had perfect knowledge of all sources of climatic factors, exact CRF history, and no other error. This minimum variance, $\sigma^{18}{ }_{\min }^{2}$, is found to be about $12\left({ }^{\circ} \mathrm{C}\right)^{2}$ for models including the CRF. Thus, once we introduce $\mathrm{CRF}$ as a driver and remove the intrinsic $\delta^{18} \mathrm{O}$ measurement variance, we can explain $75 \%$ of the paleotemperature variability.

In addition to the $\delta^{18} \mathrm{O}$ measurement errors, additional errors may arise, for example, from translation of the $\delta^{18} \mathrm{O}$ data into $\Delta T$ s that required assumptions on the ice sheet volumes (Veizer et al., 2000), from an inaccurate CRF (e.g., inaccurate knowledge of spiral arm width, amplitude, and exact phase), or from additional factors that may affect the climate (e.g., $\mathrm{CO}_{2}$, continental geography, oceanic circulation). The magnitude of such a "compound error" and its statistics can be estimated by the bootstrap method. ${ }^{5}$ Using this method, we can rule out a fluke correlation between the CRF and temperature at the $99.5 \%$ level. That is, we can

\footnotetext{
${ }^{3} g(\Phi)$ is defined such that $g(\Phi)=0,1$ for $\Phi(t)=0, \Phi$ (today) respectively. $\Phi\left(t, P_{0}\right)$ itself is one of the three CRF histories used (Fig. 2). Since theoretical estimates give a power $1 / 2$ relation between ionization rate and CCN density (Dickenson, 1975; Yu, 2002), we use the functional form of $g(x)=x^{1 / 2}-1$. We also considered other powers, but found the results to change only marginally.
}

${ }^{4} \sigma_{\min }^{2} \equiv \sum_{\mathrm{i}}\left(\Delta T_{\mathrm{i}}-\Delta T_{\text {model }}\left(t_{\mathrm{i}}\right)\right)^{2}$.
5If we had a perfect model and knowledge of the errors, then the $\chi^{2}$ of the fit should, on average, be the number of actual degrees of freedom. We therefore add errors quadratically to increase the error in the data until the modified $\chi^{2}$ per degree of freedom is 1 . If we further assume that the unknown measurement and model errors have a Gaussian distribution, we can estimate the errors in the fit parameters. To check the assumption of Gaussianity, we look at the distribution of the residual differences between the model and the best fit (model 6 in Table 1), and find that it is consistent with being Gaussian. (We expect 16.5 points larger than 1 "modified" $\sigma$, and find 15 , expect 6.9 above 1.7 modified $\sigma$ and find 4 , and expect 2.4 above $2 \sigma$ and find 3 ). 
rule out with a high confidence level models that do not include the effects of a variable $\mathrm{CRF}$. This conclusion rests on the reasonable assumption that at least one of the two "celestial" data sets with the apparent $\sim 150$ m.y. periodicity, the galactic spiral arm analyses or the iron meteorites exposure ages, is valid. While the above correlations are unlikely to be statistical flukes, we do emphasize that the data sets come with some caveats (see Shaviv, 2002b). For example, although the variable meteoritic CRF signal is statistically significant, it could still be generated in $1.2 \%$ of random realizations. In another example, it appears that actually two spiral arm pattern speeds emerge from various astronomical analyses. While the number that fits the geological and meteoritic data is supported by a strong theoretical argument (Shaviv, 2002b), the meaning of the second number is not yet resolved. Both numbers may be real, however, their meaning hinges on astrophysical considerations that are beyond the scope of this paper. 6

Armed with the above statistics, we can then place quantitative limits on the CRFclimate connection. We tested 11 models (see Table 1), varying each variable, to find the range of values that gives reasonable fits at the $68 \%$ confidence level. The normalization parameter $D$ for all these models varied between 3 and $12{ }^{\circ} \mathrm{C}$. Almost all the error in $D$ arises because we have no good limit on the amplitude of the variation of the CRF itself, except for the lower limit of 2.5 for its maximum/minimum ratio (Shaviv, 2002b). We also find an average spiral arm passage period of $P_{0}=137 \pm 4$ m.y., or $137 \pm 7$ m.y. if we consider the "jitter" from the epicyclic motion of the solar system (i.e., the noncircular motion around the Milky Way). This is consistent with the meteoritic data showing a periodicity of $143 \pm$
10 m.y. and the paleoclimate and paleotemperature data with a recurrence at $\sim 135 \pm 9$ m.y. To further check for consistency, we artificially add a lag to the predicted CRF. We find that the best lag is $-3 \pm 18 \mathrm{~m}$.y. This implies that the results are consistent with our CRF diffusion model and astronomical data on the spiral arm location. They are only marginally consistent with other possible galactic models, which predict (Shaviv, 2002b) that the actual spiral arm crossing took place $\sim 30 \mathrm{~m}$.y. before the midpoint of the high CRF-climate episode. If we include an independent analysis of the lag in the correlation between the spiral arm passages and apexes of icehouses (Shaviv, 2002b), we can exclude these alternative models at the $98 \%$ confidence level.

\section{THE MODEL IMPACT OF $\mathrm{CO}_{2}$}

Realizing that the $\mathrm{pCO}_{2}$ reconstructions are internally inconsistent, the conservative point of view is to assume at the outset that the entire residual variance that is not explained by the measurement error is due to $p \mathrm{CO}_{2}$ variations. From the model fit, we find that the temperature variance ${ }^{7} \sigma_{T\left(\mathrm{CO}_{2}\right)^{2}}$ attributable to such a " $\mathrm{CCO}_{2}$ " is at most $\left(0.62^{\circ} \mathrm{C}\right)^{2}$. To further quantify the effect of " $p \mathrm{CO}_{2}$," we need to know its variance. Considering that we are not aware of any mechanisms that would stabilize the Phanerozoic $p \mathrm{CO}_{2}$ at today's values, particularly in view of the large sources and sinks, we assume that these variations span the entire range of the existing $\mathrm{pCO}_{2}$ models (Fig. 1). With variations of this magnitude, the doubling of $\mathrm{CO}_{2}$ can account for about

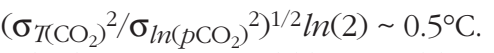
A higher impact could be possible only if it is assumed that the Phanerozoic $p \mathrm{CO}_{2}$ oscillations were limited to values close to the present-day levels.
It is entirely possible that none of the reconstructed Phanerozoic $p \mathrm{CO}_{2}$ curves (Fig. 1) is a true representation of reality. Nonetheless, we also tested eight scenarios that assume that one of the reconstructed Phanerozoic $p \mathrm{CO}_{2}$ trends (Fig. 1) is validated. To do this, we reintroduced the third term into equation 1 and considered the impact on temperature by a combined $\mathrm{CRF}$ and $\mathrm{CO}_{2}$ forcing. ${ }^{8}$ We find that, depending on the model, the introduction of $\mathrm{CO}_{2}$ as a driver reduces the $\sigma_{\min }^{2}\left[\geq 32.1\left({ }^{\circ} \mathrm{C}\right)^{2}\right]$ by only $0.5-1.5\left({ }^{\circ} \mathrm{C}\right)^{2}$, compared to $0.2-5\left({ }^{\circ} \mathrm{C}\right)^{2}$ for models that do not include CRF as a driver. That is, there is no statistically significant correlation between $p \mathrm{CO}_{2}$ and reconstructed temperature, and we cannot therefore estimate the actual driving impact of $\mathrm{CO}_{2}$.

We can, however, estimate the upper bounds of model uncertainty in terms of temperature that, potentially, could be attributable to $\mathrm{CO}_{2}$ forcing. This we can do by looking at the errors on the parameter C. Such formal $90 \%$ confidence limits are 0.91, 0.92, and $1.14^{\circ} \mathrm{C}$ for the Berner and Streif, GEOCARB III, and Rothman reconstructions, respectively. At the $99 \%$ confidence limit they are $1.67,1.46$, and $1.93{ }^{\circ} \mathrm{C}$ (Table 2). In summary, we find that with none of the $\mathrm{CO}_{2}$ reconstructions can the doubling effect of $\mathrm{CO}_{2}$ on low-latitude sea temperatures be larger than $\sim 1.9^{\circ} \mathrm{C}$, with the expected value being closer to $0.5^{\circ} \mathrm{C}$. These results differ somewhat from the predictions of the general circulation models (GCMs) (IPCC, 2001), which typically imply a $\mathrm{CO}_{2}$ doubling effect of $\sim 1.5-5.5^{\circ} \mathrm{C}$ global warming, but they are consistent with alternative lower estimates of $0.6-1.6^{\circ} \mathrm{C}$ (Lindzen, 1997).

As a qualifier, one should note that global temperature changes should exceed the tropical ones because the largest
${ }^{6}$ Although the astronomical data points to two possible spiral arm pattern speeds, a theoretical argument based on the observed outer extent of the galactic spiral arm and the spiral arm density wave theory can be made (Shaviv, 2002b). This theory, which nicely explains the spiral arm behavior in non-flocculent spiral galaxies (e.g., Binney and Tremaine, 1987), can be used to show that the observed four-armed spiral structure extending to about twice our galacto-centric radius is only consistent with a narrow range of values, including the spiral arm pattern speed which fits the meteoritic and geological data. The same argumentation can be used to show that the four-armed structure cannot extend significantly inward from our galactic radius. Since spiral arms are apparent also within our radius, they should be either two-armed, have a different spiral arm pattern speed, or both. This could naturally explain the "bimodality" in the astronomical measurements of the pattern speed. It is yet to be explained why the second number is not seen in either the meteoritic or geological data.

\footnotetext{
$\left.{ }^{7} \sigma_{T\left(\mathrm{CO}_{2}\right.}\right)^{2}=\left(\sigma_{\min }^{2}-\sigma_{18 \min }^{2}\right) / N_{\text {meas }}=\left(0.62{ }^{\circ} \mathrm{C}\right)^{2}$.

${ }^{8}$ In order to calculate the impact of combined $\mathrm{CRF}$ and $\mathrm{CO}_{2}$ forcing we used the functional form $f=1.236\left[\ln \left(c+0.0005 c^{2}\right)-\ln \left(c_{0}+0.0005 c_{0}^{2}\right)\right]$ to which the radiative driving is expected to be proportional (Hansen et al., 1998). The $c s$ are the reconstructed $\mathrm{CO}_{2}$ histories in ppm, with $c_{0}=280 \mathrm{ppm}$. The normalization is such that the value of $C$ is the temperature increase associated with a doubled $p \mathrm{CO}_{2}$. We also considered $f=\ln \left(c / c_{0}\right)$ and $f=c-c_{0}$. The former option yields similar limits on $C$, while the latter results in more stringent limits.
} 
TABLE 2: UPPER LIMIT ON LOW-LATITUDE SEA SURFACE WARMING CAUSED BY $\mathrm{CO}_{2}$ DOUBLING.

\begin{tabular}{|c|c|c|c|}
\hline \multirow[t]{2}{*}{$\mathrm{CO}_{2}$ History } & \multicolumn{3}{|c|}{ Upper limit $\left[{ }^{\circ} \mathrm{C}\right]$ (at various confidence levels) ${ }^{*}$} \\
\hline & $68 \%$ & $90 \%$ & $99 \%$ \\
\hline GEOCARB III & 0.39 & 0.92 & 1.46 \\
\hline Rothman & 0.70 & 1.14 & 1.93 \\
\hline Berner and Streif & 0.07 & 0.91 & 1.67 \\
\hline Independent ${ }^{\dagger}$ & $\sim 0.5$ & & \\
\hline \multicolumn{4}{|c|}{$\begin{array}{l}{ }^{*} \text { The confidence levels assume that the unknown sources of error have a Gaussian } \\
\text { distribution. The distribution of residual errors is consistent with this assumption. } \\
{ }^{\dagger} \text { The independent result assumes only that all the residual variance (not explained by CRF } \\
\text { variability or } \delta^{18} \mathrm{O} \text { measurement error) is due to } p \mathrm{CO}_{2} \text {, and that } \sigma^{2}\left(\ln \left(p \mathrm{CO}_{2}\right)\right) \sim \mathrm{O}(1) \text {. }\end{array}$} \\
\hline
\end{tabular}

temperature variations are in the high-latitude regions for which we do not have any isotope record. A review of GCMs (IPCC, 2001) shows that the globally averaged warming from $\mathrm{CO}_{2}$ is expected to be typically 1.5 times larger than that of the tropical temperatures, and our model uncertainty limits should therefore be modified accordingly. Note also that the bootstrapping "compound error" includes, among others, any error associated with the ice volume correction. Taking an unrealistic ultimate scenario that assumes no ice volume correction at all, the amplitude of temperature oscillations in Figure 2 could be almost doubled. While these and similar considerations may help in expanding somewhat the above calculated temperature limits potentially attributable to $\mathrm{CO}_{2}$, they will not alter the relative importance of the celestial- $\mathrm{CO}_{2}$ forcings. The model impact of CRF will increase in tandem with that of $\mathrm{CO}_{2}$ for any change in the amplitude of $\Delta T$. As a final qualification, we emphasize that our conclusion about the dominance of the CRF over climate variability is valid only on multimillion year time scales. At shorter time scales, other climatic factors may play an important role, but note that many authors (see previous references) suggest a decisive role for the celestial driver also on multi-millennial to less than annual time scales.

\section{POTENTIAL IMPLICATIONS}

Our approach, based on entirely independent studies from astrophysics and geosciences, yields a surprisingly consistent picture of climate evolution on geological time scales. At a minimum, the results demonstrate that the approach is potentially viable, as is the proposition that celestial phenomena may be important for understanding the vagaries of the planetary climate. Pending further confir- mation, one interpretation of the above result could be that the global climate possesses a stabilizing negative feedback. A likely candidate for such a feedback is cloud cover (Lindzen, 1997; Ou, 2001). If so, it would imply that the water cycle is the thermostat of climate dynamics, acting both as a positive (water vapor) and negative (clouds) feedback, with the carbon cycle "piggybacking" on, and being modified by, the water cycle (Nemani et al., 2002; Lovett, 2002; Lee and Veizer, 2003). It is our hope that this study may contribute to our understanding of the complexities of climate dynamics and ultimately to quantification of its response to potential anthropogenic impact.

\section{ACKNOWLEDGMENTS}

This research was supported by the F.I.R.S.T. (Bikura) program of the Israel Science Foundation (grant no. 4048/03), the Deutsche Forschungsgemeinschaft, the Natural Sciences and Engineering Council of Canada, and the Canadian Institute for Advanced Research.

\section{REFERENCES CITED}

Beer, J., Mende, W., and Stellmacher, R., 2000, The role of the sun in climate forcing: Quaternary Science Review, v. 19, p. 403-415. vised model of atmospheric $\mathrm{CO}_{2}$ over Phanerozoic time: American Journal of Science, v. 301, p. 182-204.

Berner, U., and Streif, H., 2001, Klimafakten Der RückblickVerlagsbuchhandlung, Science Publishers, 238 p.

Björck, S., Muscheler, R., Kromer, B., Andersen, C.S., Heinemeier, J., Johnsen, S.J., Conley, D., Koç, N., Spurk, M., and Veski, S., 2001, High resolution analyses of an early Holocene climate event may imply decreased solar forcing as

Binney, J.J., and Tremaine, S., 1987, Galactic dynamics: Princeton, Princeton University Press, 755 p.

Bond, G., Kromer, B., Beer, J., Muscheler, R., Evans, M.N., Showers, W., Hoffmann, S., Lotti-Bond, R., Hajdas, I., and Bonani, G., 2001, Persistent solar influence on North Atlantic climate during the Holocene: Science, v. 294 p. 2130-2136.

Boucot, A.J., and Gray, J., 2001, A critique of Phanerozoic climatic models involving changes in the $\mathrm{CO}_{2}$ content of the atmosphere: Earth Science Reviews, v. 56, p. 1-159.
Berner, R.A., and Kothavala, Z., 2001, GEOCARB III: A reEin Schlüssel für die Zukunft: Stuttgart, E. Schweizerbart'sche an important climate driver: Geology, v. 29, p. 1101-1110.
Caillon, N., Severinghaus, J.P., Jouzel, J., Barnola, J.-M., Kang, J., and Lipenkov V.Y., 2003, Timing of atmospheric $\mathrm{CO}_{2}$ and Antarctic temperature changes across Termination III: Science, v. 299 , p. $1728-1731$.

Clarke, T., 2003, Bubbles prompt climate-change rethink: Nature, Science Update, http://www.nature.com/nsu/030310/ 030310-12.html (April 2003).

Dickenson, R.-E., 1975, Solar variability and the lower atmosphere: Bulletin of the American Meteorological Society, v. 56, p. $1240-1248$.

Egorova, L.Y., Vovk, V.Ya., and Troshichev, O.A., 2000, Influence of variations of the cosmic rays on atmospheric pressure and temperature in the southern geomagnetic pole region: Journal of Atmospheric and Solar-Terrestrial Physics, v. 62 , p. 955-966.

Eichkorn, S., Wilhelm, S., Aufmhoff, H., Wohlfrom, K.H., and Arnold, F., 2002, Cosmic ray-induced aerosol formation: First observational evidence from aircraft based ion mass spectrometer measurements in the upper troposphere: Geophysical Research Letters, v. 29, 10.1029/2002GL015044.

Fields, B.D., and Ellis, J., 1999, On deep-ocean Fe-60 as a fossil of a near-earth supernova: New Astronomy, v. 4, p. 419-430.

Fischer, H., Wahlen, M., Smith, J., Mastroianni, D., and Deck, B., 1999, Ice core record of atmospheric $\mathrm{CO}_{2}$ around the last three glacial terminations: Science, v. 283, p. 1712-1714.

Frakes, L.A., and Francis, J.E., 1988, A guide to Phanerozoic cold polar climates from high latitude ice-rafting in the Cretaceous: Nature, v. 333, p. 547-549.

Frakes, L.A., Francis, E., and Syktus, J.I., 1992, Climate modes of the Phanerozoic; The history of the Earth's climate over the past 600 million years: Cambridge, Cambridge University Press, $286 \mathrm{p}$.

Friis-Christensen, E., and Lassen, K., 1991, Length of the solar cycle: an indicator of solar activity closely associated with climate: Science, v. 254, p. 698-700.

Hansen, J.E., Sato, M., Lacis, A., Ruedy, R., Tegen, I., and Matthews, E., 1998, Climate forcings in the industrial era: Proceedings of the National Academy of Sciences, v. 95, p. $12,753-12,758$.

Harrison, R.G., and Aplin, K.L., 2001, Atmospheric condensation nuclei formation and high-energy radiation: Journal of Atmospheric Terrestrial Physics, v. 63, p. 1811-1819.

Hodell, D.A., Brenner, M., Curtis, J.H., and Guilderson, J.H., 2001, Solar forcing of drought frequency in the Maya lowlands: Science, v. 292, p. 1367-1370.

Hoffman, P.F., Kaufman, A.J., Halverson, G.P., and Schrag, D.P., 1998, A Neoproterozoic snowball Earth: Science, v. 281 , p. $1342-1346$.

Intergovernmental Panel on Climate Change (IPCC), 2001, Contribution of Working Group 1 to the third assessment report of the IPCC, Houghton, J.T., et al., eds., Climate change 2001: The scientific basis: Cambridge, Cambridge University Press, 892 p.

Kasting, J.F., and Ackerman, T.P., 1986, Climate consequences of very high $\mathrm{CO}_{2}$ levels in the Earth's early atmosphere: Science, v. 234, p. 1383-1385.

Kirkby, J., editor, 2001, CLOUD: A particle beam facility to investigate the influence of cosmic rays on clouds, in Proceedings of the Workshop on lon-Aerosol-Cloud Interactions, CERN: Geneva, CERN 2001-007 175, also at http://cloud.web.cern.ch/cloud/ (April 2003).

Kromer, B., Freidrich, M., and Spurk, M., 2001, Natürliche Klimavariationen im Spätglazial und Holozän im Spiegel von Baumringserien: Nova Acta Leopoldina, v. NF88, p. 141-159.

Labitzke, K., and Weber, K., 2001, Insolations-Wechsel als Anfachung hochfrequenter Klima-Oszillationen: Nova Acta Leopoldina, v. NF88, p. 161-172.

Lee, D., and Veizer, J., 2003, Water and carbon cycles in the Mississippi river basin: potential implications for the northern hemisphere "residual terrestrial sink": Global Biogeochemical Cycles, v. 17, no. 2, DOI: 10.1029/2002GB001984.

Lindzen, R.S., 1997, Can increasing carbon dioxide cause climate change?: Proceedings of the National Academy of Sciences, v. 94, p. 8335-8342.

Lovett, R.A., 2002, Global warming: Rain might be leading carbon sink factor: Science, v. 296, p. 1787. 
Marsh, N.D., and Svensmark, H., 2000, Low cloud properties influenced by cosmic rays: Physical Review Letters, v. 85 , p. 5004-5007.

Marsh, N.D., and Svensmark, H., 2003, Galactic cosmic ray and El Niño-Southern Oscillation trends in ISCCP-D2 low cloud properties: Journal of Geophysical Research, v. 108, no. D6, p. 4195, DOI: 10.1029/2001JD001264.

Monnin, E., Indermühle, A., Dällenbach, A., Flückiger, J., Stauffer, B., Stocker, T.R., Raynaud, D., and Barnola, J.M., 2001, Atmospheric $\mathrm{CO}_{2}$ concentrations over the last glacial terminations: Nature, v. 291, p. 112-114.

Mudelsee, M., 2001, The phase relations among atmospheric $\mathrm{CO}_{2}$ content, temperature and global ice volume over the past 420 ka: Quaternary Science Review, v. 20, p. 583-589.

Neff, U., Burns, S.J., Mangnini, A., Mudelsee, M., Fleitmann, D., and Matter, A., 2001, Strong coherence between solar variability and the monsoon in Oman between 9 and $6 \mathrm{kyr}$ ago: Nature, v. 411, p. 290-293.

Nemani, R., White, M., Thornton, P., Nishida, K., Reddy, S., Jenkins, J., and Running, S., 2002, Recent trends in hydrologic balance have enhanced the terrestrial carbon sink in the United States: Geophysical Research Letters, v. 29 , p. 106-1-106-4.

Ney, E.P., 1959, Cosmic radiation and weather: Nature, v. 183 , p. $451-452$.

Ou, H.-W., 2001, Possible bounds on the Earth's surface temperature: From the perspective of conceptual global mean model: Journal of Climate, v. 14, p. 2976-2988.

Pang, K.D., and Yau, K.K., 2002, Ancient observations link changes in Sun's brightness and Earth's climate: Eos (Transactions, American Geophysical Union), v. 83, p. $481-490$.

Petit, J.R., Jouzel, J., Raynaud, D., Barkov, N.I., Barnola, J.-M Basile, I., Benders, M., Chappellaz, J., Davis, M., Delayque, G., Delmotte, M., Kotlyakov, V.M., Legrand, M., Lipenkov, V.Y., Lorius, C., Pépin, L., Ritz, C., Saltzman, E., and

Stievenard, M., 1999, Climate and atmospheric history of the past 420,000 years from the Vostok ice core, Antarctica: Nature, v. 399, p. 429-436.

Pierrehumbert, R.T., 2002, The hydrologic cycle in deep-time climate problems: Nature, v. 419, p. 191-198.

Rothman, D.H., 2002, Atmospheric carbon dioxide levels for the last 500 million years: Proceedings of the National Academy of Sciences, v. 99, p. 4167-4171.

Shaviv, N.J., 2002a, Cosmic ray diffusion from the galactic spiral arms, iron meteorites, and a possible climatic connection?: Physical Review Letters, v. 89, 051102.

Shaviv, N.J., 2002b, The spiral structure of the Milky Way, cosmic rays, and ice age epochs on Earth: New Astronomy, v. 8, p. 39-77.

Solanki, S.K., 2002, Solar variability and climate change: is there a link?: Astronomy \& Geophysics, v. 43, p. 5.9-5.13.

Soon, W.H., Posmentier, E.S., and Baliunas, S.L., 1996, Inference of solar irradiance variability from terrestrial temperature changes, 1880-1993: An astrophysical application of the Sun-climate connection: The Astrophysical Journal v. 472, p. 891-902.

Soon, W.H., Posmentier, E.S., and Baliunas, S.L., 2000 Climate hypersensitivity to solar forcing?: Annales Geophysicae, v. 18, p. 583-588.

Svensmark, H., 1998, Influence of cosmic rays on Earth's climate: Physical Review Letters, v. 81, p. 5027-5030.

Tinsley, B.A., and Deen, G.W., 1991, Apparent tropospheric response to $\mathrm{MeV}-\mathrm{GeV}$ particle flux variations: A connection via electrofreezing of supercooled water in high-level clouds? Journal of Geophysical Research, v. 12, p. 22,283-22,296.

Tinsley, B.A., and Yu, F., 2003, Effect of particle flux variations on clouds and climate, in Popp, J., et al., eds., Solar Variability and its Effect on the Earth's Atmospheric and Climate System: Washington, D.C., American Geophysical Union Monograph (in press).

Todd, M.C., and Kniveton, D.R., 2001, Changes in cloud cover associated with Forbush decreases of galactic cosmic rays: Journal of Geophysical Research—Atmospheres, v. 106, p. 32,031-32,041

Veizer, J., Ala, D., Azmy, K., Bruckschen, P., Buhl, D., Bruhn, F., Carden, G.A.F., Diener, A., Ebneth, S., Goddéris, Y., Jasper, T., Korte, C., Pawellek, F., Podlaha, O.G., and Strauss, H., $1999{ }^{87} \mathrm{Sr} /{ }^{86} \mathrm{Sr}, \delta^{13} \mathrm{C}$ and $\delta^{18} \mathrm{O}$ evolution of Phanerozoic seawater: Chemical Geology, v. 161, p. 59-88.

Veizer, J., Godderis, Y., and Francois, L.M., 2000, Evidence for decoupling of atmospheric $\mathrm{CO}_{2}$ and global climate during the Phanerozoic eon: Nature, v. 408, p. 698-701.

Wallmann, K., 2001, The geological water cycle and the evolution of marine $\delta^{18} \mathrm{O}$ values: Geochimica et Cosmochimica Acta, v. 65, p. 2469-2485.

Yu, F., 2002, Altitude variations of cosmic ray induced production of aerosols: Implications for global cloudiness and climate: Journal of Geophysical Research, v. 107, no. A7, DOI: $10.1029 / 20011000248$.

Manuscript submitted February 24, 2003; accepted April 24, 2003. 